\title{
Bone mineral density: testing for osteoporosis
}

\section{SUMMARY}

Primary osteoporosis is related to bone loss from ageing. Secondary osteoporosis results from specific conditions that may be reversible.

A thoracolumbar X-ray is useful in identifying vertebral fractures, and dual energy X-ray absorptiometry is the preferred method of calculating bone mineral density. The density of the total hip is the best predictor for a hip fracture, while the lumbar spine is the best site for monitoring the effect of treatment.

The T-score is a comparison of the patient's bone density with healthy, young individuals of the same sex. A negative T-score of -2.5 or less at the femoral neck defines osteoporosis.

The Z-score is a comparison with the bone density of people of the same age and sex as the patient. A negative Z-score of -2.5 or less should raise suspicion of a secondary cause of osteoporosis.

Clinical risk calculators can be used to predict the 10-year probability of a hip or major osteoporotic fracture. A probability of more than $5 \%$ for the hip or more than $20 \%$ for any fracture is abnormal and treatment may be warranted.

\section{Introduction}

Osteoporosis is a common systemic skeletal disorder leading to decreased bone strength and increased susceptibility to osteofragility fracture. It is a significant health issue that affects up to one million Australians.

Primary osteoporosis refers to bone loss that occurs due to the normal ageing process, while secondary osteoporosis results from specific clinical disorders that are potentially reversible. Correctly treating an underlying cause may ameliorate fracture risk and avoids unnecessary treatment with antiresorptive drugs.

The diagnosis of osteoporosis is based on the presence of a fracture after minimal trauma or by detecting low bone mineral density. There are different imaging modalities (Table) but dual energy $X$-ray absorptiometry is the preferred method.

Eligibility for treatment under the Pharmaceutical Benefits Scheme (PBS) requires confirmation of a minimal trauma fracture or low bone mineral density.

\section{Spinal radiography}

Vertebral fractures are often missed and can be asymptomatic, or present with progressive kyphosis, loss of height, or chronic back pain. A vertebral fracture can be defined as a $20 \%$ or greater reduction in anterior height versus posterior vertebral body height (see Fig.). The presence of a vertebral fracture is highly predictive of a subsequent fracture, but if the fracture is asymptomatic the patient may be left untreated and at risk.

In a large Australian community-based study of women aged over 70 and not known to have osteoporosis, thoracolumbar X-ray detected at least one vertebral fracture in $24.7 \%$. In the same cohort, dual energy X-ray absorptiometry found $21.8 \%$ had osteoporosis at the femoral neck or lumbar spine. However, only $7.3 \%$ had both osteoporosis on dual energy X-ray absorptiometry and a vertebral fracture on thoracolumbar X-ray. ${ }^{2}$ Up to $50 \%$ of women with vertebral fractures have normal bone mineral density by dual energy $\mathrm{X}$-ray absorptiometry, so potentially a third of women will not be diagnosed by this method. ${ }^{3}$

A thoracolumbar X-ray should therefore be performed in patients who have symptoms of a vertebral fracture, decreased bone mineral density on dual energy X-ray absorptiometry at the hip, or multiple clinical risk factors for osteoporosis. While spinal radiography is essential for diagnosing a vertebral fracture, it is important not to confuse the spinal deformity of an osteoporotic fracture from other causes including spondylosis.

Another method for detecting vertebral fractures is through vertebral fracture assessment using dual energy X-ray absorptiometry. Multiple studies have

\section{Angela Sheu \\ Advanced trainee \\ Conjoint associate lecturer ${ }^{2}$ \\ Terry Diamond \\ Senior endocrinologist \\ Associate professor \\ Endocrinology 2 \\ 'Department of \\ Endocrinology \\ St George Hospita \\ ${ }^{2}$ University of New South Wales \\ Sydney}

\section{Key words}

bone densitometry, bone density, fracture of bone, osteoporosis

Aust Prescr 2016;39:35-9 http://dx.doi.org/10.18773/ austprescr.2016.020 


\section{Table Comparison of different technologies for measuring bone mineral density}

\begin{tabular}{|c|c|c|c|c|c|}
\hline Test & Radiation* & Sites & Advantages & Disadvantages & Clinical use \\
\hline DXA & $\begin{array}{l}\text { Minimal } \\
\text { (4 microsievert) }\end{array}$ & $\begin{array}{l}\text { Hip, spine, } \\
\text { forearm }\end{array}$ & $\begin{array}{l}\text { High precision, } \\
\text { reproducible, correlates } \\
\text { well with fracture risk }\end{array}$ & $\begin{array}{l}\text { Affected by many artefacts, } \\
\text { including previous fractures, } \\
\text { spinal pathology, extrinsic } \\
\text { artefacts, obesity }\end{array}$ & $\begin{array}{l}\text { Hip bone mineral density best } \\
\text { predictor for hip fracture. Lumbar } \\
\text { spine bone mineral density best for } \\
\text { monitoring treatment effect }\end{array}$ \\
\hline QCT & $\begin{array}{l}\text { High } \\
\text { (200 microsievert at } \\
\text { spine, } 1200 \text { microsievert } \\
\text { at hip) }\end{array}$ & Hip, spine & $\begin{array}{l}\text { Selective measurement } \\
\text { of trabecular and cortical } \\
\text { bone, true volumetric bone } \\
\text { mineral density }\end{array}$ & $\begin{array}{l}\text { Less reproducible, less } \\
\text { standardisation, fewer analysis } \\
\text { protocols }\end{array}$ & $\begin{array}{l}\text { Sensitive for monitoring vertebral } \\
\text { bone loss and treatment effect, } \\
\text { especially in known spinal disease or } \\
\text { artefacts }\end{array}$ \\
\hline pQCT & $\begin{array}{l}\text { Minimal } \\
\text { (3-5 microsievert) }\end{array}$ & $\begin{array}{l}\text { Distal bone } \\
\text { (usually } \\
\text { radius, tibia) }\end{array}$ & $\begin{array}{l}\text { Compact and mobile } \\
\text { machines }\end{array}$ & $\begin{array}{l}\text { Small peripheral regions only, } \\
\text { slow changes over time }\end{array}$ & Children \\
\hline HR-pQCT & $\begin{array}{l}\text { Minimal } \\
\text { ( } 5 \text { microsievert) }\end{array}$ & Tibia, radius & $\begin{array}{l}\text { Non-invasive measurement } \\
\text { of microarchitecture, } \\
\text { structure and mechanical } \\
\text { strength }\end{array}$ & $\begin{array}{l}\text { Small peripheral regions only, } \\
\text { expensive machinery }\end{array}$ & $\begin{array}{l}\text { Research tool for non-invasive } \\
\text { determination of bone structure }\end{array}$ \\
\hline QUS & None & $\begin{array}{l}\text { Calcaneus, } \\
\text { radius, tibia }\end{array}$ & $\begin{array}{l}\text { Portable, no ionising } \\
\text { radiation }\end{array}$ & $\begin{array}{l}\text { Not standardised, } \\
\text { operator dependent, poor } \\
\text { reproducibility }\end{array}$ & $\begin{array}{l}\text { May be able to predict fracture } \\
\text { risk, but conflicting evidence for } \\
\text { monitoring while on treatment }\end{array}$ \\
\hline
\end{tabular}

* Daily background radiation approximately 5 microsievert, standard chest X-ray 20-60 microsievert

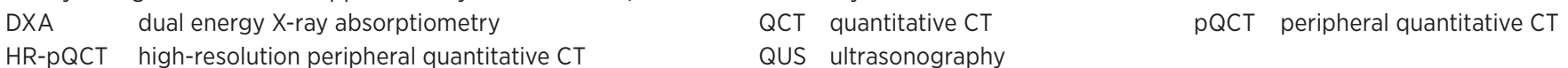

Fig. Compression fracture of L1 vertebra

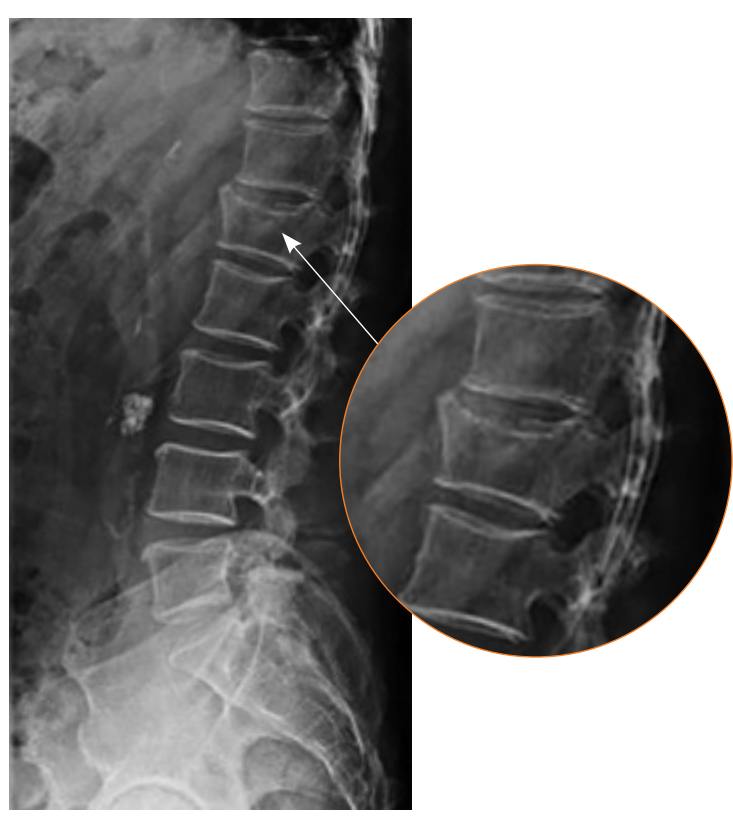

shown moderately good concordance between absorptiometry and thoracolumbar X-ray in identifying vertebral fractures. ${ }^{4-6}$ Limitations include adequate visualisation of the upper thoracic spine and potentially confounding spinal diseases.

\section{Bone mineral density}

By current criteria, a bone mineral density at the femoral neck equal to or less than 2.5 standard deviations below the mean for a young person of the same sex is diagnostic of osteoporosis. This is reported as a T-score of -2.5 or less. Prescribing criteria for antiresorptive treatment are based predominantly on the T-score, so measuring bone mineral density is usually required before treatment.

A screening measurement is reimbursed by Medicare for patients over 70 years old, in the absence of a minimal trauma fracture or secondary cause of osteoporosis. For patients who have sustained a minimal trauma fracture, measuring bone mineral density is not required for the diagnosis of osteoporosis or to fulfil some PBS prescribing criteria for osteoporosis. However, a baseline measurement is useful before starting treatment.

The Z-score is the number of standard deviations away from the mean bone mineral density of a person of the same age and sex. A Z-score below -2.5 should raise suspicion of a secondary cause of osteoporosis.

\section{Dual energy X-ray absorptiometry}

The most commonly used technique for measuring bone mineral density is dual energy $\mathrm{X}$-ray absorptiometry. This harnesses the high sensitivity of calcium in absorbing $\mathrm{X}$-rays to measure the relative 
amounts of bone and other soft tissue, in order to calculate bone mineral content and hence density (Table). Absolute measurements from different machines differ significantly so standardised reference ranges should be used. Serial measurements should be performed on the same machine to identify true changes in the patient's bone mineral density.

Dual energy X-ray absorptiometry is versatile and can be used to measure bone mineral density at various body sites. Of the four potential sites at the hip (total hip, femoral neck, trochanteric region and Ward's triangle), the density of the total hip is recommended due to its high precision, reproducibility and correlation with fracture risk. ${ }^{7}$ Measurements at the lumbar spine are also highly reproducible, but can be heavily influenced by artefacts. The forearm may be used when the hip or spine cannot be measured or interpreted, but there can be a significant difference in bone mineral density between the dominant and non-dominant arm. ${ }^{8}$ Current evidence shows that bone mineral density at the hip is the most reliable for predicting hip fracture risk, and spinal bone mineral density should be used for monitoring treatment. ${ }^{9}$ Technical factors can affect measurements made by dual energy X-ray absorptiometry. Commonly there are false elevations due to vertebral disease, such as osteoarthritic spondylosis, osteophytes, scoliosis or vertebral fracture, or extrinsic artefacts from calcifications and surgical metalwork. Obesity may alter the calculated bone mineral density. Osteomalacia may lead to underestimates due to decreased bone mineralisation. Acquisition errors in patient positioning and other physical artefacts can usually be overcome by trained staff, quality control and regular services of the machines. Correct positioning is critical for accurate measurements and should be confirmed by the clinician. For optimal hip measurements, the femur should be internally rotated so that the lesser trochanter is not seen. Spine images should be centred, straight and not rotated.

\section{Computed tomography}

Quantitative CT generates a reconstructed threedimensional image and calculates bone density when calibrated to a reference object of known density. It measures true volumetric bone mineral density and is not limited by the patient's size or vertebral deformities. ${ }^{10}$ Results can occasionally be spuriously low in a patient with normal T-scores on dual energy $\mathrm{X}$-ray absorptiometry. It is suspected this is due to increased marrow fat with advancing age which affects the assessment of bone density when measured by CT. Quantitative CT may also be used to assess a patient who is suspected of having a falsely elevated bone mineral density on dual energy $\mathrm{X}$-ray absorptiometry due to osteoarthritis. Limitations of CT include higher doses of radiation, less reproducibility and fewer standardised reference ranges and analysis protocols.

Peripheral quantitative $\mathrm{CT}$ requires machines specifically designed for distal bone sites (usually radius or tibia). Its use is mostly limited to children.

High-resolution CT has spatial resolution that allows imaging of individual trabeculae. This is a non-invasive method of viewing three-dimensional microarchitecture and trabecular and cortical structure. Radiation is minimal, scan time is relatively short (approximately three minutes) and scan precision is acceptable, making this an attractive method for determining bone structure, although it is currently limited to research centres.

\section{Ultrasound}

Ultrasonography calculates bone stiffness as a surrogate for bone density and is most commonly used on the calcaneus." Clinical studies suggest that ultrasonography can predict hip fractures ${ }^{12}$ and vertebral fractures ${ }^{13}$ in a similar way to bone mineral density. Benefits include no ionising radiation, and portability of the machine. Its limitations include significant manufacturer and operator differences. Ultrasound is not currently recommended for screening for osteoporosis.

\section{Risk factors}

Apart from low bone mineral density, a number of clinical risk factors for fractures have been identified and should be used together with the bone mineral density to calculate an individual's fracture risk (Box 1).14,15 Peak bone mass is achieved by age 30 . Bone loss occurs steadily from the age of about 40 (0.3-0.5\% per year), with accelerated loss in the perimenopausal period (4-6\% per year) before slowing again after the age of 70 (1-2\% per year) $).^{16} \mathrm{Age}$ is therefore the strongest predictor for fracture risk.

\section{Box 1 Clinical risk factors for fracture ${ }^{14,15}$}

High fracture risk:

Age $>70$ years

Low body weight or significant weight loss

Physical inactivity (including secondary to chronic illness or spinal cord injury)

Drugs: corticosteroids ( $\geq 5 \mathrm{mg}$ prednisolone daily or equivalent for $\geq 3$ months), anticonvulsants, thiazolidinediones, selective serotonin reuptake inhibitors, thyroxine, aromatase inhibitors, chemotherapy

Current smoking

Alcohol ( $\geq 2$ standard drinks/day)

History of fragility fracture

Parental history of hip fracture

Low sunlight exposure 


\section{SELF-TEST QUESTIONS}

True or false?

1. The radiation dose from dual energy X-ray absorptiometry is approximately double the dose of a standard chest X-ray.

2. Up to $50 \%$ of women with vertebral fractures have normal bone mineral density when measured by dual energy X-ray absorptiometry.

Answers on page 66

\section{Assessing fracture risk}

Although bone mineral density provides an estimation of osteoporosis, it is insufficient for predicting an individual's fracture risk. Clinical risk models, such as the FRAX too ${ }^{17}$ and the Garvan fracture risk calculator ${ }^{18}$ use bone mineral density and clinical factors to predict an individual's absolute fracture risk. The patient's risk of falls is also essential in risk stratification.

FRAX* has been the most extensively used tool worldwide and calculates the 10-year risk for a hip or major osteoporotic fracture (hip, clinical spine, humerus or wrist). By combining clinical risk factors with bone mineral density and age, the sensitivity of fracture prediction improves without reducing specificity. A 10-year probability of a hip fracture more than $5 \%$, or of a major osteoporotic fracture more than $20 \%$, is significant and antiresorptive treatment should be considered (see case study in Box 2). The main limitation of FRAX is the dichotomised risk factors (presence or absence of a parameter) rather than quantifying each risk factor. For example, two previous fractures increase the risk much more than a single previous fracture, and increased total consumption (duration and dose) of glucocorticoids, tobacco and alcohol are associated with greater fracture risk. A further limitation is that the algorithm only uses the T-score measured by femoral neck dual energy X-ray absorptiometry. The applicability of FRAX to patients

\footnotetext{
*www.shef.ac.uk/FRAX/tool.aspx?country=31
}

with discordant T-scores at other sites or the use of different technologies has yet to be determined.

The Garvan fracture risk calculator can be used with or without a measurement of bone mineral density. It quantifies the number of fractures and takes into account the patient's history of falls. The calculator gives both a 5-year and 10-year risk for a hip or any fracture and is useful when a measurement of bone mineral density cannot be performed or interpreted. Its main limitation is the absence of other clinical risk factors in the risk calculation.

\section{Conclusion}

Osteoporosis is a common disorder that affects many Australians. Preventing fractures is crucial to reducing the associated morbidity and healthcare costs.

Diagnosing osteoporosis requires a careful search for fragility fractures and measuring bone mineral density. Thoracolumbar X-ray may reveal an asymptomatic vertebral fracture, which significantly increases the individual's risk for a further fracture. Dual energy X-ray absorptiometry is the preferred method of measuring bone mineral density as it has excellent precision, minimal radiation and is useful in predicting a fracture and for monitoring treatment. Combining the bone mineral density with clinical risk factors in risk calculators can quantify a patient's fracture risk and can guide specific treatment. $<$

Conflict of interest: none declared

\section{Box 2 Case study: calculating fracture probability ${ }^{17}$}

A 72-year-old female with no personal or family history of a fracture and no other high-risk features and a femoral neck bone mineral density T-score of -2.7 , has a $9.3 \%$ probability of any osteoporotic fracture and $4.2 \%$ probability of a hip fracture in 10 years (see A). If the same patient had previously sustained a fracture, her probabilities would increase to $14 \%$ and $6.2 \%$ (see B), placing her at high risk of hip fracture and therefore treatment would be warranted.

\section{A. FRAX-calculated 10-year probability of a fracture}

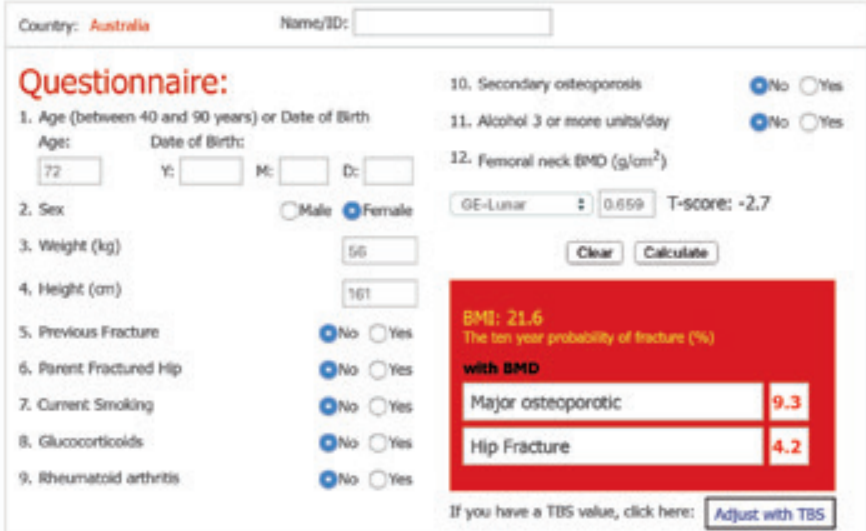

B. FRAX-calculated 10-year probability of a fracture for the same patient with the additional risk factor of a previous fracture

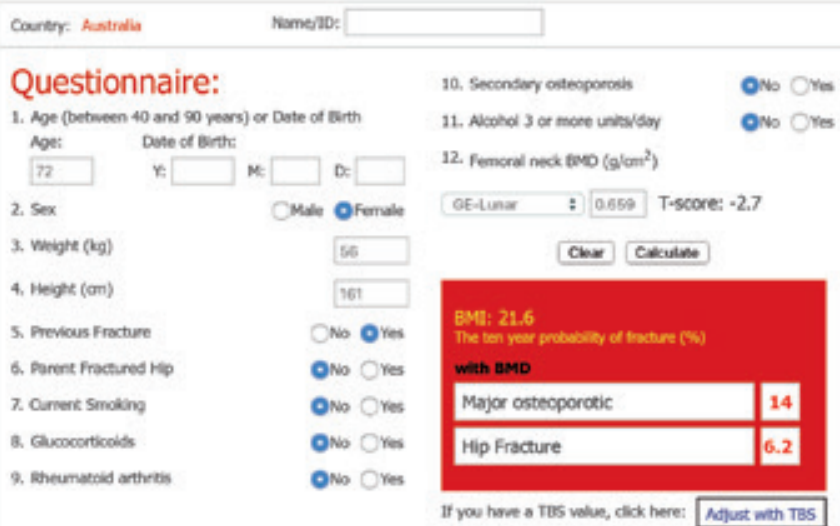


1. Watts JJ, Abimanyi-Ochom J, Sanders KM. Osteoporosis costing all Australians: a new burden of disease analysis 2012 to 2022. Glebe: Osteoporosis Australia; 2012. www.osteoporosis.org.au/sites/default/files/files/ Burden\%20of\%20Disease\%20Analysis\%202012-2022.pdf [cited 2016 Mar 1]

2. Davis SR, Kirby C, Weekes A, Lanzafame A, Piterman L. Simplifying screening for osteoporosis in Australian primary care: the Prospective screening for osteoporosis; Australian primary care evaluation of clinical tests (PROSPECT) study. Menopause 2011;18:53-9. http://dx.doi.org/10.1097/ gme.0b013e3181e77468

3. Greenspan SL, von Stetten E, Emond SK, Jones L, Parker RA. Instant vertebral assessment: a noninvasive dual X-ray absorptiometry technique to avoid misclassification and clinical mismanagement of osteoporosis. J Clin Densitom 2001;4:373-80. http://dx.doi.org/10.1385/JCD:4:4:373

4. Genant HK, Li J, Wu CY, Shepherd JA. Vertebral fractures in osteoporosis: a new method for clinical assessment. J Clin Densitom 2000;3:281-90. http://dx.doi.org/10.1385/ JCD:3:3:281

5. Schousboe JT, Debold CR. Reliability and accuracy of vertebral fracture assessment with densitometry compared to radiography in clinical practice. Osteoporos Int 2006;17:281-9. http://dx.doi.org/10.1007/s00198-005-2010-5

6. Chapurlat RD, Duboeuf F, Marion-Audibert HO, Kalpakçioglu B, Mitlak BH, Delmas PD. Effectiveness of instant vertebral assessment to detect prevalent vertebral fracture. Osteoporos Int 2006;17:1189-95. http://dx.doi.org/ 10.1007/s00198-006-0121-2

7. Arabi A, Baddoura R, Awada H, Khoury N, Haddad S, Ayoub G, et al. Discriminative ability of dual-energy X-ray absorptiometry site selection in identifying patients with osteoporotic fractures. Bone 2007;40:1060-5. http://dx.doi.org/10.1016/j.bone.2006.11.017

8. El Maghraoui A, Roux C. DXA scanning in clinical practice. QJM 2008:101:605-17. http://dx.doi.org/10.1093/qjmed/ hcnO22

9. Blake GM, Fogelman I. The role of DXA bone density scans in the diagnosis and treatment of osteoporosis. Postgrad Med J 2007;83:509-17. http://dx.doi.org/10.1136/pgmj.2007.057505
10. Adams JE. Quantitative computed tomography. Eur J Radiol 2009;71:415-24. http://dx.doi.org/10.1016/ j.ejrad.2009.04.074

11. Bonnick SL. Bone densitometry in clinical practice: application and interpretation. 3rd ed. Humana Press; 2009. http://dx.doi.org/10.1007/978-1-60327-499-9

12. Bauer DC, Glüer CC, Cauley JA, Vogt TM, Ensrud KE, Genant HK, et al.; Study of Osteoporotic Fractures Research Group. Broadband ultrasound attenuation predicts fractures strongly and independently of densitometry in older women. A prospective study. Arch Intern Med 1997:157:629-34. http://dx.doi.org/10.1001/archinte.1997.00440270067006

13. Glüer CC, Eastell R, Reid DM, Felsenberg D, Roux C, Barkmann R, et al. Association of five quantitative ultrasound devices and bone densitometry with osteoporotic vertebral fractures in a population-based sample: the OPUS Study. J Bone Miner Res 2004:19:782-93. http://dx.doi.org/10.1359/ jbmr.040304

14. Kanis JA. Assessment of osteoporosis at the primary healthcare level. WHO Scientific Technical Report. World Health Organization Collaborating Centre for Metabolic Bone Diseases, University of Sheffield, UK; 2007.

15. Kanis JA, McCloskey EV, Johansson H, Cooper C, Rizzoli R, Reginster JY; Scientific Advisory Board of the European Society for Clinical and Economic Aspects of Osteoporosis and Osteoarthritis (ESCEO) and the Committee of Scientific Advisors of the International Osteoporosis Foundation (IOF). European guidance for the diagnosis and management of osteoporosis in postmenopausal women. Osteoporos Int 2013;24:23-57. http://dx.doi.org/10.1007/s00198-012-2074-y

16. Diamond T, Tonks K. Secondary causes of osteoporosis in women: diagnoses not to be missed. Med Today 2008:9:48-62.

17. Kanis JA, Johnell O, Oden A, Johansson H, McCloskey E. FRAX and the assessment of fracture probability in men and women from the UK. Osteoporos Int 2008:19:385-97. http://dx.doi.org/10.1007/s00198-007-0543-5

18. Nguyen ND, Frost SA, Center JR, Eisman JA, Nguyen TV. Development of prognostic nomograms for individualizing 5 -year and 10-year fracture risks. Osteoporos Int 2008;19:1431-44. http://dx.doi.org/10.1007/s00198-008-0588-0

\section{NPS MEDICINEWISE}

\section{Osteoporosis case study}

In this free, online interactive case study you'll meet Richard, 57, discharged from hospital after a recent admission for an infective exacerbation of chronic obstructive pulmonary disease (COPD). During his stay a chest X-ray revealed a vertebral fracture. How would you investigate Richard's osteoporotic risk factors? What treatment options are available for Richard? How can you help Richard improve his adherence to his medicines?

- CPD points available for GPs, pharmacists and nurses

- For GPs: recognised for the Practice Incentives Program Quality Prescribing Incentive

- Receive instant feedback

- Compare your approach with your peers

- Expert commentary by leading Australian endocrinologist, Professor John Eisman

Register now at nps.org.au/osteoporosis-case-study 